\title{
Comparison of two endogenous biomarkers of CYP3A4 activity in a drug-drug interaction study between midostaurin and rifampicin
}

\author{
Catherine Dutreix • Sebastien Lorenzo $\cdot$ Yanfeng Wang
}

Received: 20 February 2014 / Accepted: 27 March 2014 / Published online: 21 May 2014

(C) The Author(s) 2014. This article is published with open access at Springerlink.com

\begin{abstract}
Purpose Midostaurin, a multitargeted tyrosine kinase inhibitor, is primarily metabolized by CYP3A4. This midostaurin drug-drug interaction study assessed the dynamic response and clinical usefulness of urinary $6 \beta$-hydroxycortisol to cortisol ratio $(6 \beta C R)$ and plasma $4 \beta$-hydroxycholesterol $(4 \beta \mathrm{HC})$ for monitoring CYP3A4 activity in the presence or absence of rifampicin, a strong CYP3A4 inducer.

Methods Forty healthy adults were randomized into groups for either placebo or treatment with rifampicin $600 \mathrm{mg}$ QD for 14 days. All participants received midostaurin $50 \mathrm{mg}$ on day 9. Midostaurin plasma pharmacokinetic parameters were assessed. Urinary $6 \beta \mathrm{CR}$ and plasma $4 \beta \mathrm{HC}$ levels were measured on days $1,9,11$, and 15 .

Results Both markers remained stable over time in the control group and increased significantly in the rifampicin group. In the rifampicin group, the median increases (vs day 1) on days 9,11 , and 15 were 4.1-, 5.2-, and 4.7-fold, respectively, for $6 \beta C R$ and 3.4-, 4.1-, and 4.7-fold, respectively, for $4 \beta \mathrm{HC}$. Inter- and intrasubject variabilities in the control group were $45.6 \%$ and $30.5 \%$, respectively, for $6 \beta \mathrm{CR}$, and $33.8 \%$ and $7.5 \%$, respectively, for $4 \beta \mathrm{HC}$. Baseline midostaurin area under the concentration-time curve (AUC) correlated with $4 \beta \mathrm{HC}$ levels ( $\rho=-0.72 ; P=.003)$, but not with $6 \beta \mathrm{CR}(\rho=0.0925 ; P=.6981)$.
\end{abstract}

Electronic supplementary material The online version of this article (doi:10.1007/s00228-014-1675-0) contains supplementary material, which is available to authorized users.

C. Dutreix $\cdot$ S. Lorenzo

Novartis Pharma AG Basel, Basel, Switzerland

Y. Wang

Novartis Pharmaceuticals, East Hanover, NJ, USA

Present Address:

Y. Wang $(\bowtie)$

Isis Pharmaceuticals, Carlsbad, CA, USA

e-mail: ywang@isisph.com
Conclusions Both $6 \beta C \mathrm{CR}$ and $4 \beta \mathrm{HC}$ levels showed a good dynamic response range upon strong CYP3A4 induction with rifampicin. Because of lower inter- and intrasubject variability, $4 \beta \mathrm{HC}$ appeared more reliable and better predictive of CYP3A4 activity compared with $6 \beta C R$. The data from our study further support the clinical utility of these biomarkers.

Keywords Midostaurin - Rifampicin - CYP3A4 biomarker . $4 \beta$-hydroxycholesterol $\cdot 6 \beta$-hydroxycortisol to cortisol ratio

\section{Introduction}

Cytochrome P450 3A4 (CYP3A4), the most abundant human CYP isoform [1], is involved in the metabolism of approximately half of all marketed drugs [2]. However, there is large intersubject variability in the expression and activity of CYP3A4, resulting from both genetic and nongenetic factors [3]. Sensitive probes such as midazolam are often used as exogenous markers to assess the in vivo activity of CYP3A4 $[4,5]$. In contrast to exogenous markers, urinary $6 \beta$-hydroxycortisol to cortisol ratio $(6 \beta C R)$ and plasma $4 \beta$-hydroxycholesterol $(4 \beta \mathrm{HC})$ levels are endogenous biomarkers of CYP3A4 activity [6-14]. Indicative of cortisol and cholesterol metabolism by CYP3A4, respectively, urinary $6 \beta C R$ and plasma $4 \beta \mathrm{HC}$ rise with increasing CYP3A4 activity [13, 15]. Besides being endogenous, these biomarkers are measured less invasively or noninvasively, making them attractive candidate markers for studies that involve monitoring pharmacokinetics (PK) and pharmacodynamics at multiple time points.

Midostaurin (PKC412; N-benzoylstaurosporin), a multitargeted tyrosine kinase inhibitor with activity in acute myeloid leukemia [16] and advanced systemic mastocytosis [17-19], is a sensitive CYP3A4 substrate [20]. Previously, we assessed plasma $4 \beta \mathrm{HC}$ level and urinary $6 \beta \mathrm{CR}$ in the rifampicin induction part of a drug-drug interaction study [20]. The goals of this analysis were to further evaluate the dynamic range of 
these biomarkers upon strong induction with rifampicin and to compare and evaluate whether these biomarkers can serve as covariates to explain intersubject variability of midostaurin pharmacokinetics in a clinical setting.

\section{Methods}

Study population and design

The study population and study design have been reported previously [20]. Briefly, healthy adults aged 18 to 55 years weighing 50 to $90 \mathrm{~kg}$ and with a body mass index (BMI) of 18 to $29.9 \mathrm{~kg} / \mathrm{m}^{2}$ were randomized $1: 1$ to receive placebo or rifampicin $600 \mathrm{mg}$ once daily in the evening on days 1 through 14 (Fig. 1; Electronic Supplementary Material [ESM]-Methods). All subjects received midostaurin $50 \mathrm{mg}$ on day 9 .

\section{Pharmacokinetics and biomarker assessments}

As described previously [20], a validated liquid chromatography/ tandem mass spectrometry (LC-MS/MS) assay was used to assess midostaurin, rifampicin, and $4 \beta \mathrm{HC}$ levels in plasma and $6 \beta$-hydroxycortisol and cortisol levels in urine. Missing values were not imputed, and analyte concentrations below the lower limit of quantitation were treated as zero values. Additional details are reported in the ESM-Methods.

\section{Statistical analysis}

The $4 \beta \mathrm{HC}$ concentrations and $6 \beta \mathrm{CR}$ were log-transformed and analyzed for each treatment group (placebo, rifampicin) with a linear mixed-effects model with visit (days 1, 9, 11, and 15) as fixed effect and subject as random effect. Point estimates and a corresponding $90 \% \mathrm{CI}$ of differences in visits were computed and antilogged to provide the GMR and $90 \%$ $\mathrm{CI}$ of change in $4 \beta \mathrm{HC}$ and $6 \beta \mathrm{CR}$ (day $9 /$ day 1 , day 11 /day 1 , and day $15 /$ day 1 ) by treatment group. The intersubject and intrasubject variabilities of $4 \beta \mathrm{HC}$ and $6 \beta \mathrm{CR}$ for each treatment were provided using the linear mixed-effect models. The correlation between the area under the concentration-time curve from time zero to infinity $\left(\mathrm{AUC}_{\mathrm{inf}}\right)$ of midostaurin and biomarkers $(4 \beta \mathrm{HC}$ and $6 \beta \mathrm{CR})$ was investigated with the Pearson correlation coefficient by treatment group.

\section{Results}

Baseline characteristics

Baseline characteristics in the PK population $(N=40,20$ in each arm) were balanced between study arms (Table 1). Most participants were male $(60.0 \%)$, and the majority were white (95.0\%). Median age, weight, and BMI were 44 years, $78.2 \mathrm{~kg}$, and $24.9 \mathrm{~kg} / \mathrm{m}^{2}$, respectively.

\section{$4 \beta \mathrm{HC}$ levels and $6 \beta C \mathrm{R}$}

Evidence of CYP3A4 induction and midostaurin PK are discussed in the ESM-Results. At baseline (day 1), $4 \beta \mathrm{HC}$ showed an intersubject variability of approximately $36 \%$ in the midostaurin+rifampicin group and approximately $34 \%$ in the midostaurin + placebo group. In the presence of rifampicin, the geometric mean estimate $(90 \% \mathrm{CI})$ of plasma $4 \beta \mathrm{HC}$ concentration in the midostaurin + rifampicin arm showed increases of 3.4-fold (3.2-3.6), 4.1-fold (3.8-4.3), and 4.6-fold (4.4-5.0) between day 1 and days 9,11 , and 15 , respectively; variability ranged from $26 \%$ to $29 \%$ (Table 2 ; Fig. 2). In the midostaurin + placebo arm, the plasma $4 \beta \mathrm{HC}$ concentrations remained stable over time, as did intersubject variability (geometric $\mathrm{CV} \% \approx 36 \%$ ). Based on similar $4 \beta \mathrm{HC}$ levels in the placebo group, the intrasubject variability was estimated to be $7.5 \%$. There were no significant differences in $4 \beta \mathrm{HC}$ levels between males and females in either study arm (ESMSupplemental Table 1).

The intersubject variability at baseline was slightly higher for $6 \beta \mathrm{CR}(\approx 48 \%)$ than for $4 \beta \mathrm{HC}(\approx 36 \%)$. In the presence of rifampicin, the geometric mean estimate $(90 \% \mathrm{CI})$ of $6 \beta \mathrm{CR}$ showed 4.1-fold (3.4-4.8), 5.2-fold (4.4-6.2), and 4.7-fold
Fig. 1 Study design. $Q D$ once daily, $P K$ pharmacokinetic

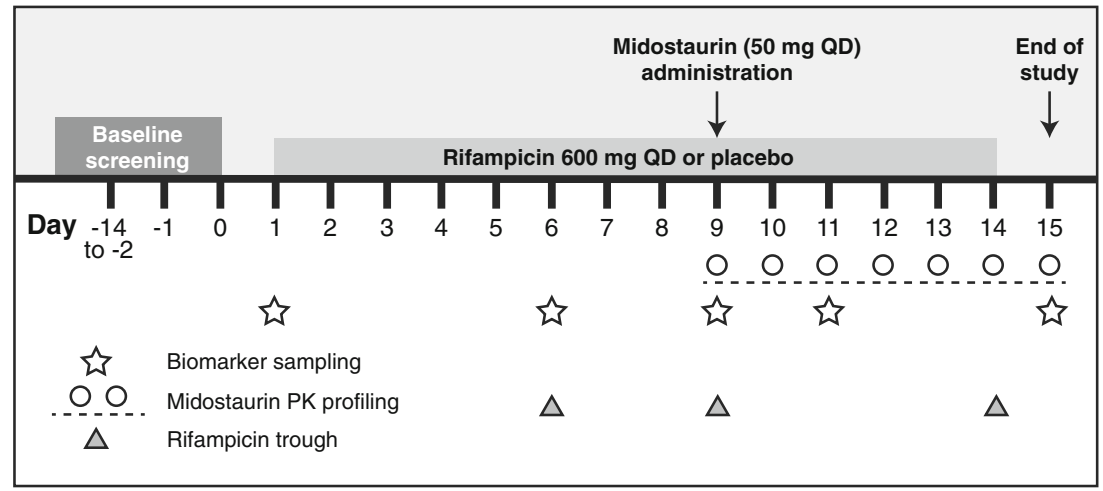


Table 1 Baseline demographics of the pharmacokinetics population

\begin{tabular}{llll}
\hline & $\begin{array}{l}\text { Midostaurin+Rifampicin } \\
(n=20)\end{array}$ & $\begin{array}{l}\text { Midostaurin+Placebo } \\
(n=20)\end{array}$ & $\begin{array}{l}\text { All Participants } \\
(N=40)\end{array}$ \\
\hline Median age (range), y & $40(23-52)$ & $46(30-53)$ & $44(23-53)$ \\
Male, $n(\%)$ & $12(60.0)$ & $12(60.0)$ & $24(60.0)$ \\
White, $n(\%)$ & $19(95.0)$ & $19(95.0)$ & $38(95.0)$ \\
Median weight (range) $\mathrm{kg}$ & $77.8(55-89)$ & $78.3(57-89)$ & $78.2(55-89)$ \\
Median BMI (range), $\mathrm{kg} / \mathrm{m}^{2}$ & $24.5(21-29)$ & $25.1(20-30)$ & $24.9(20-30)$
\end{tabular}

$B M I$ body mass index

(4.0-5.6) increases between day 1 and days 9, 11, and 15, respectively. The variability remained high in the rifampicin treatment group. In the placebo arm, the $6 \beta C R$ values remained stable over time despite a high variability on day 15 . Based on the repeated measurements in the placebo group, the intrasubject variability for $6 \beta \mathrm{CR}$ was estimated to be $30.5 \%$.

Correlation between midostaurin AUC and CYP3A4

biomarker levels at baseline

In the placebo arm, midostaurin AUC correlated well with $4 \beta \mathrm{HC}$ levels at baseline $(\rho=-0.72 ; P=.0003)$, but not with $6 \beta \mathrm{CR}$ at baseline $(\rho=0.0925 ; P=.6981 ;$ Fig. 3$)$. In the pooled dataset that included the placebo and rifampicin groups, a clear separation of plasma $4 \beta \mathrm{HC}$ concentrations was observed between participants in the midostaurin + rifampicin arm (>55 $\mathrm{ng} / \mathrm{mL}$ in all participants) and those in the midostaurin + placebo $\operatorname{arm}(\leq 55 \mathrm{ng} / \mathrm{mL}$ in all participants) after induction (Table 2). Considering all samples from days 9,11 , and 15 , plasma $4 \beta \mathrm{HC}$ concentrations were higher in participants in the rifampicin arm (range, $55.5 \mathrm{ng} / \mathrm{mL}-183.0 \mathrm{ng} / \mathrm{mL}$ ) than in those in the placebo arm (range, $11.9 \mathrm{ng} / \mathrm{mL}-53.0 \mathrm{ng} / \mathrm{mL}$ ). However, for urinary
$6 \beta C R$, pooled data showed significant overlap between the rifampicin and placebo groups (ranges 10.10-117.82 and 3.38-53.13, respectively), likely due to the large observed variability of the urine biomarker.

\section{Discussion}

Both $6 \beta \mathrm{CR}$ and $4 \beta \mathrm{HC}$ level are well-known endogenous biomarkers for CYP3A4 activity [6-14]. CYP3A4/5 catalyzes the formation of $6 \beta$-hydroxycortisol from cortisol, both of which are excreted in urine [6]. Single-spot urine collection can be used to measure $6 \beta \mathrm{CR}[8,15]$. CYP3A4/ 5 also catalyzes the formation of $4 \beta \mathrm{HC}$, which is formed from cholesterol [21]. Recent studies suggest that both $6 \beta \mathrm{CR}$ and $4 \beta \mathrm{HC}$ are viable and sensitive biomarkers for CYP3A4 activity; both showed good correlation with changes of the exogenous sensitive probe substrate midazolam when it was coadministered with rifampicin or ketoconazole $[12,14]$.

In the current study, healthy volunteers were administered a clinically relevant dose of rifampicin to induce CYP3A4

Table 2 Changes in biomarker levels over time in each treatment arm

\begin{tabular}{|c|c|c|c|c|c|c|}
\hline & \multicolumn{3}{|c|}{ Midostaurin+Rifampicin } & \multicolumn{3}{|c|}{ Midostaurin+Placebo } \\
\hline & \multicolumn{3}{|l|}{$(n=20)$} & \multicolumn{3}{|l|}{$(n=20)$} \\
\hline & $\begin{array}{l}\text { Geometric Mean } \\
(\mathrm{CV} \%)\end{array}$ & Range & $\begin{array}{l}\text { Fold Increase } \\
(90 \% \mathrm{CI})\end{array}$ & $\begin{array}{l}\text { Geometric Mean } \\
(\mathrm{CV} \%)\end{array}$ & Range & $\begin{array}{l}\text { Fold Increase } \\
(90 \% \mathrm{CI})\end{array}$ \\
\hline \multicolumn{7}{|c|}{$4 \beta \mathrm{HC}, \mathrm{ng} / \mathrm{mL}$} \\
\hline Day 1 & $22.03(36.45)$ & $14.1-59.2$ & 1.0 (baseline) & $25.33(34.25)$ & $12.3-54.5$ & 1.0 (baseline) \\
\hline Day 9 & $74.35(27.17)$ & $55.5-152.0$ & $3.4(3.15-3.61)$ & $23.38(34.60)$ & $12.5-48.5$ & $0.9(0.89-0.96)$ \\
\hline Day 11 & $89.46(29.47)$ & $59.6-183.0$ & $4.1(3.79-4.35)$ & $25.43(33.85)$ & $12.9-50.9$ & $1.0(0.97-1.04)$ \\
\hline Day 15 & $102.70(25.54)$ & $69.5-178.0$ & $4.6(4.36-4.99)$ & $23.28(36.27)$ & $11.9-53.0$ & $0.9(0.88-0.96)$ \\
\hline \multicolumn{7}{|l|}{$6 \beta C R$} \\
\hline Day 1 & $6.83(47.75)$ & $2.46-13.31$ & 1.0 (baseline) & $9.22(46.64)$ & $4.85-20.00$ & 1.0 (baseline) \\
\hline Day 9 & $27.73(56.80)$ & $10.10-75.20$ & $4.1(3.42-4.82)$ & $6.92(57.03)$ & $3.38-21.90$ & $0.8(0.64-0.88)$ \\
\hline Day 11 & $35.42(53.63)$ & $12.83-85.91$ & $5.2(4.37-6.15)$ & $9.21(50.81)$ & $5.89-41.03$ & $1.0(0.85-1.17)$ \\
\hline Day 15 & $32.14(83.58)$ & $11.46-117.82$ & $4.7(3.96-5.58)$ & $7.49(70.58)$ & $3.45-53.13$ & $0.8(0.69-0.95)$ \\
\hline
\end{tabular}

$4 \beta H C 4 \beta$-hydroxycholesterol, $6 \beta C R 6 \beta$-hydroxycortisol to cortisol ratio, $C V \%$ percent coefficient of variation 
Fig. 2 Plasma $4 \beta \mathrm{HC}$ levels and $6 \beta C R$ over time in both the control (midostaurin + placebo) and treatment (midostaurin+ rifampicin) groups (arithmetic mean \pm SD). $4 \beta H C$

$4 \beta$-hydroxycholesterol, $6 \beta C R 6 \beta$-hydroxycortisol to cortisol ratio
$4 \beta \mathrm{HC}$

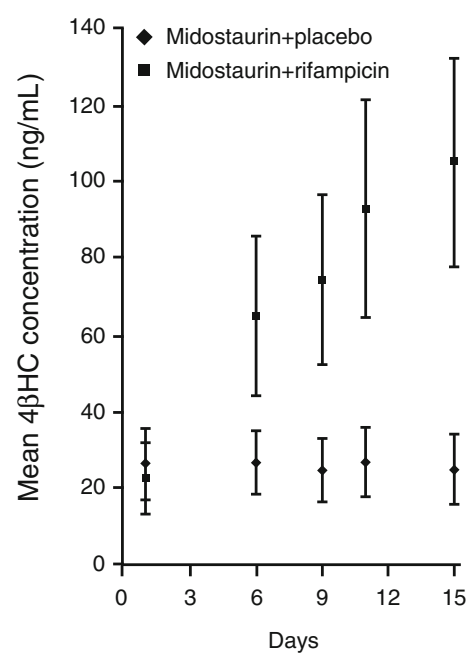

$6 \beta C R$

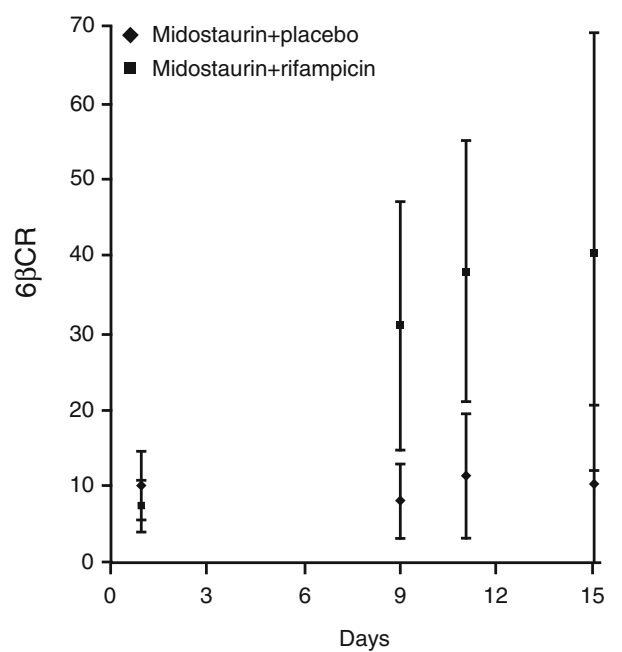

activity. CYP3A4 induction was associated with a notable increase in urinary $6 \beta \mathrm{CR}$ and plasma $4 \beta \mathrm{HC}$ concentrations, demonstrating that both $6 \beta \mathrm{CR}$ and $4 \beta \mathrm{HC}$ level can be used to monitor CYP3A4 activity. Levels of $4 \beta \mathrm{HC}$ had lower intersubject and intrasubject variability than $6 \beta \mathrm{CR}$ did, consistent with the long half-life of $4 \beta \mathrm{HC}$ in humans (17 days) [9]. Because $4 \beta \mathrm{HC}$ level is less variable within the sample subject, it can serve as a reliable biomarker for the baseline level of CYP3A4 activity in vivo. Midostaurin is a sensitive substrate of CYP3A4, as shown by the $94 \%$ drop in AUC in the presence of rifampicin and a more than 10-fold increase with ketoconazole [20]. A high correlation coefficient of $\rho=-0.72$ between midostaurin AUC and $4 \beta \mathrm{HC}$ level suggests that a large portion (52\%) of the PK variability for midostaurin could be explained by CYP3A4 variability as reflected by different $4 \beta \mathrm{HC}$ levels. For drugs less sensitive to CYP3A4 metabolism, the correlation is likely to be less significant. The PK exposure-biomarker correlation analysis provides an added value of measuring baseline levels of $4 \beta \mathrm{HC}$ for drugs metabolized primarily by CYP3A4 in clinical studies. Additionally, prior work showed that $4 \beta \mathrm{HC}$ level was higher in women than in men [22]; while our data showed a similar trend, the differences were not significant.

While there was higher inter- and intrasubject variability in urinary $6 \beta C \mathrm{C}$ compared with plasma $4 \beta \mathrm{HC}$ levels, CYP3A4 induction was demonstrated more quickly with $6 \beta C R$ than
Fig. 3 Correlation between midostaurin $\mathrm{AUC}_{\text {inf }}$ and $4 \beta \mathrm{HC}$ levels or $6 \beta C R$ (day 9) in the placebo control group (upper panel) and in the placebo control plus rifampicin treatment groups combined (lower panel). $4 \beta H C$ $4 \beta$-hydroxycholesterol, $6 \beta C R$ $6 \beta$-hydroxycortisol to cortisol ratio, $A U C_{\text {inf }}$ area under the concentration-time curve from time zero to infinity
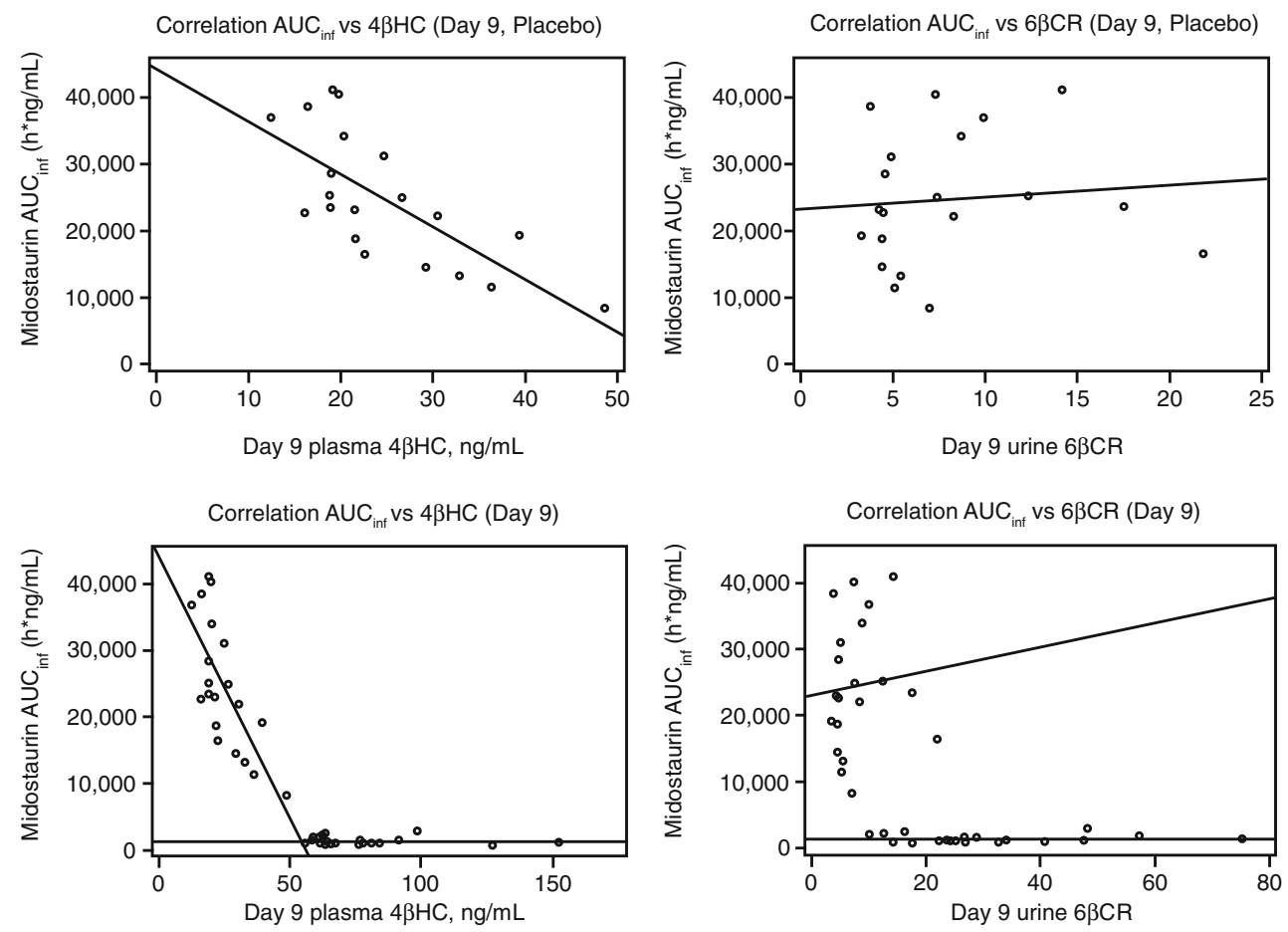
with $4 \beta \mathrm{HC}$ level. Urinary $6 \beta C \mathrm{C}$ increased 4.1 -fold by day 9 , close to the average plateau range between days 11 and 15 , whereas the levels of $4 \beta \mathrm{HC}$ showed a continued increase between days 9 and 15 , apparently due to its long half-life as discussed above. Although both cortisol and $6 \beta$ hydroxycortisol have a diurnal effect, their ratio remains stable over time $[15,23]$. A steady state can be reached rather rapidly because of the short half-life of cortisol and its metabolite (approximately $1 \mathrm{~h}$ ) [24], with little delay or lag time behind the changes of CYP3A4 activity in vivo. Thus, $6 \beta C R$ and $4 \beta \mathrm{HC}$ may complement each other as CYP3A4 biomarkers. If a stable biomarker is needed, $4 \beta \mathrm{HC}$ would be the first choice. However, if a more rapid biomarker is necessary, $6 \beta C R$ would be the marker of choice. If the outcome is unknown, as for new molecular entities, using both biomarkers in clinical studies would be recommended. Further studies may be warranted to evaluate whether the variability of $6 \beta C R$ can be reduced or better managed.

Acknowledgments Financial support for medical editorial assistance was provided by Novartis Pharmaceuticals Corporation. Antonin Schmitt, PharmD, PhD, helped in data analysis during his postdoctoral work at Novartis Pharmaceuticals Corporation. We thank Karen Kaluza, $\mathrm{PhD}$, and Pamela Tuttle, $\mathrm{PhD}$, for medical editorial assistance with this manuscript.

Contributions of authors Catherine Dutreix: Conception and design, acquisition of data, analysis and interpretation of data, drafting of the manuscript, critical revision of the manuscript for important intellectual content, and final approval of the manuscript

Sebastien Lorenzo: Conception and design, acquisition of data, analysis and interpretation of data, drafting of the manuscript, critical revision of the manuscript for important intellectual content, and final approval of the manuscript

Yanfeng Wang: Conception and design, acquisition of data, analysis and interpretation of data, drafting the manuscript, critical revision of the manuscript for important intellectual content, and final approval of the manuscript

Open Access This article is distributed under the terms of the Creative Commons Attribution License which permits any use, distribution, and reproduction in any medium, provided the original author(s) and the source are credited.

\section{References}

1. Frye RF (2004) Probing the world of cytochrome P450 enzymes. Mol Interv 4:157-162

2. Foti RS, Rock DA, Wienkers LC, Wahlstrom JL (2010) Selection of alternative CYP3A4 probe substrates for clinical drug interaction studies using in vitro data and in vivo simulation. Drug Metab Dispos 38:981-987

3. Lamba JK, Lin YS, Schuetz EG, Thummel KE (2002) Genetic contribution to variable human CYP3A-mediated metabolism. Adv Drug Deliv Rev 54:1271-1294

4. Lepper ER, Baker SD, Permenter M, Ries N, van Schaik RH, Schenk PW, Price DK, Ahn D, Smith NF, Cusatis G, Ingersoll RG, Bates SE,
Mathijssen RH, Verweij J, Figg WD, Sparreboom A (2005) Effect of common CYP3A4 and CYP3A5 variants on the pharmacokinetics of the cytochrome $\mathrm{P} 450$ 3A phenotyping probe midazolam in cancer patients. Clin Cancer Res 11:7398-7404

5. Racha JK, Zhao ZS, Olejnik N, Warner N, Chan R, Moore D, Satoh $\mathrm{H}$ (2003) Substrate dependent inhibition profiles of fourteen drugs on CYP3A4 activity measured by a high throughput LCMS/MS method with four probe drugs, midazolam, testosterone, nifedipine and terfenadine. Drug Metab Pharmacokinet 18:128-138

6. Ged C, Rouillon JM, Pichard L, Combalbert J, Bressot N, Bories P, Michel H, Beaune P, Maurel P (1989) The increase in urinary excretion of 6 beta-hydroxycortisol as a marker of human hepatic cytochrome P450IIIA induction. Br J Clin Pharmacol 28:373-387

7. Bodin K, Bretillon L, Aden Y, Bertilsson L, Broome U, Einarsson C, Diczfalusy U (2001) Antiepileptic drugs increase plasma levels of 4beta-hydroxycholesterol in humans: evidence for involvement of cytochrome p450 3A4. J Biol Chem 276:38685-38689

8. Chen YC, Gotzkowsky SK, Nafziger AN, Kulawy RW, Rocci ML Jr, Bertino JS Jr, Kashuba AD (2006) Poor correlation between 6betahydroxycortisol:cortisol molar ratios and midazolam clearance as measure of hepatic CYP3A activity. Br J Clin Pharmacol 62:187-195

9. Diczfalusy U, Kanebratt KP, Bredberg E, Andersson TB, Bottiger Y, Bertilsson L (2009) 4beta-hydroxycholesterol as an endogenous marker for CYP3A4/5 activity. Stability and half-life of elimination after induction with rifampicin. Br J Clin Pharmacol 67:38-43

10. Tomalik-Scharte D, Lutjohann D, Doroshyenko O, Frank D, Jetter A, Fuhr U (2009) Plasma 4beta-hydroxycholesterol: an endogenous CYP3A metric? Clin Pharmacol Ther 86:147-153

11. Diczfalusy U, Nylen H, Elander P, Bertilsson L (2011) 4betaHydroxycholesterol, an endogenous marker of CYP3A4/5 activity in humans. Br J Clin Pharmacol 71:183-189

12. Bjorkhem-Bergman L, Backstrom T, Nylen H, Ronquist-Nii Y, Bredberg E, Andersson TB, Bertilsson L, Diczfalusy U (2013) Comparison of endogenous 4beta-hydroxycholesterol with midazolam as markers for CYP3A4 induction by rifampicin. Drug Metab Dispos 41:1488-1493

13. Marde Arrhen Y, Nylen H, Lovgren-Sandblom A, Kanebratt KP, Wide K, Diczfalusy U (2013) A comparison of 4betahydroxycholesterol/cholesterol and 6beta-hydroxycortisol/cortisol as markers of CYP3A4 induction. Br J Clin Pharmacol 75:15361540

14. Shin KH, Choi MH, Lim KS, Yu KS, Jang IJ, Cho JY (2013) Evaluation of endogenous metabolic markers of hepatic CYP3A activity using metabolic profiling and midazolam clearance. Clin Pharmacol Ther 94:601-609

15. Tran JQ, Kovacs SJ, McIntosh TS, Davis HM, Martin DE (1999) Morning spot and 24-hour urinary 6 beta-hydroxycortisol to cortisol ratios: intraindividual variability and correlation under basal conditions and conditions of CYP 3A4 induction. J Clin Pharmacol 39: 487-494

16. Stone RM, DeAngelo DJ, Klimek V, Galinsky I, Estey E, Nimer SD, Grandin W, Lebwohl D, Wang Y, Cohen P (2005) Patients with acute myeloid leukemia and an activating mutation in FLT3 respond to a small-molecule FLT3 tyrosine kinase inhibitor, PKC412. Blood 105: $54-60$

17. Gotlib J, DeAngelo DJ, George TI, Corless CL, Linder A, Langford C, Dutreix C, Gross S, Nikolova Z, Graubert T (2010) KIT inhibitor midostaurin exhibits a high rate of clinically meaningful and durable responses in advanced systemic mastocytosis: report of a fully accrued phase II trial. Blood 116:abstract 316

18. Gotlib J, Kluin-Nelemans HC, George TI, Akin C, Sotlar K, Hermine O, Awan F, Hexner E, Mauro M, Morariu R, Squier M, Villeneuve M, Emery-Salbert F, Hartmann K, Horny HP, Valent P, Reiter A (2012) KIT inhibitor midostaurin in patients with advanced systemic mastocytosis: results of a planned interim analysis of the global CPKC412D2201 trial. Blood 120:799 
19. Gotlib J, Kluin-Nelemans HC, George TI, Akin C, Sotlar K, Hermine O, Awan F, Hexner E, Mauro M, Morariu R, Squier M, Villeneuve M, Emery-Salbert F, Coombs J, Hartmann K, Horny H, Valent P, Reiter A (2013) Durable responses and improved quality of life with midostaurin (PKC412) in advanced systemic mastocytosis (SM): updated stage 1 results of the global D2201 trial. Blood 122:106

20. Dutreix C, Munarini F, Lorenzo S, Roesel J, Wang Y (2013) Investigation of CYP3A4-mediated drug-drug interactions on midostaurin in healthy volunteers. Cancer Chemother Pharmacol 72:1223-1234

21. Bodin K, Andersson U, Rystedt E, Ellis E, Norlin M, Pikuleva I, Eggertsen G, Bjorkhem I, Diczfalusy U (2002) Metabolism of 4 beta -hydroxycholesterol in humans. J Biol Chem 277:31534-31540
22. Diczfalusy U, Miura J, Roh HK, Mirghani RA, Sayi J, Larsson H, Bodin KG, Allqvist A, Jande M, Kim JW, Aklillu E, Gustafsson LL, Bertilsson L (2008) 4Beta-hydroxycholesterol is a new endogenous CYP3A marker: relationship to CYP3A5 genotype, quinine 3hydroxylation and sex in Koreans, Swedes and Tanzanians. Pharmacogenet Genomics 18:201-208

23. Lee C (1995) Urinary 6 beta-hydroxycortisol in humans: analysis, biological variations, and reference ranges. Clin Biochem 28:4954

24. Weitzman ED, Fukushima D, Nogeire C, Roffwarg H, Gallagher TF, Hellman L (1971) Twenty-four hour pattern of the episodic secretion of cortisol in normal subjects. J Clin Endocrinol Metab $33: 14-22$ 